\title{
Real-time evacuation route selection method for complex buildings
}

\author{
ARTURO CUESTA, ORLANDO ABREU, ADRIANA BALBOA and DANIEL ALVEAR \\ GIDAI Group \\ University of Cantabria \\ Los Castros s/n CP 39005, Santander, Spain
}

\begin{abstract}
This paper proposes a new real-time decision method to select optimal evacuation routes. The mathematical formulation, the solution algorithm and the computer model are presented. The optimization algorithm is based on the stochastic evacuation model predictions by considering emergency data such as the location of the hazard. The method was applied to an industrial building. The stochastic evacuation model was compared with the commercial evacuation model STEPS involving 14 potential evacuation routes and the computational model was applied to 10 hypothetical emergency scenarios to demonstrate its validity.
\end{abstract}

KEYWORDS: Real-time evacuation route selection, evacuation modeling, evacuation management

\section{NOMENCLATURE LISTING}

$\begin{array}{llll}A_{v} & \text { availability for evacuation } & n_{i x} & \text { number of columns of the grid } \\ C_{i x, j y} & \text { grid cell } & n_{j y} & \text { number of rows of the grid } \\ D_{f i t}(x) & \text { Distribution fitting of } x \text { variable } & n_{k}(i, j) & \text { total number of available routes from } i \text {-th location to } j \text {-th exit } \\ d_{\text {travel }} & \text { travel distance }(\mathrm{m}) & P_{0.95} & \begin{array}{l}\text { 95-th percentile } \\ G\end{array} \\ i & \text { set of grid cells } & R & \text { set of evacuation routes available } \\ j & \text { number of the location of evacuees } & \hat{R} & \text { Set of disabled evacuation routes } \\ k & \text { number of the exit } & R_{E R} & \text { set of selected evacuation routes } \\ m_{r u n} & \text { number of the evacuation route } & T_{\text {evac }} & \text { evacuation time (s) } \\ m_{w_{i}} & \text { number of simulations } & T_{p r e} & \text { pre-evacuation time }(\mathrm{s}) \\ & & v & \text { walking speed }(\mathrm{m} / \mathrm{s})\end{array}$

\section{INTRODUCTION}

In case of a fire incident in a building, timely and efficient evacuation decisions can avoid injuries and save lives. Of particular concern is an appropriate evacuation route selection to optimize evacuation process and minimize the risk for occupants. There are many papers in the literature devoted to this issue [1-12]. Approaches to this problem can be divided into macro and microscopic models [13]. The former approaches are dynamic network flow models mainly used to calculate the optimal evacuation times [1417], whereas microscopic approaches concentrate on the simulation of individual behaviors [18-23]. Both macro and microscopic approaches can be used for evacuation planning. It is well known that an emergency never happens exactly the way that it was predicted to happen. Current evacuation instructions provided to occupants, based on static plans and signaling, do not take into account the changing conditions during the course of the emergency. In such circumstances, occupants may well use inappropriate or even dangerous routes to leave the building.

Despite of the fact that a good evacuation planning can improve fire safety, much effort need to be done. A key point is the possibility of analyzing and predicting the impact of different evacuation scenarios and procedures during the course of the emergency and that is why fire safety science is opening to new modeling opportunities focused on real-time applications [24-29]. These applications require: 1 ) inputs directly from the situation 2) model or models that should run faster than real-time events 3) processing the outputs quickly enough and 4) information easy to interpret and with a high confidence level.

This paper aims to present a real-time decision method for the selection of optimal evacuation routes to minimize evacuation times and occupant exposure to the detected hazard. The method includes the mathematical model, the optimization algorithm and the computer model. The optimization algorithm is based on the stochastic evacuation model predictions which registers the evacuation time for all occupants through all available evacuation routes in each simulation. The evacuation time of each occupant depends upon the pre-evacuation time, travel speed and travel distance. In addition, the method takes into account the location of threat. Finally, the computational model is able to run 1.000 simulations and provide the user a set of optimal evacuation routes within a few seconds. The paper is divided into four parts. In the first part, the proposed method that includes the mathematical formulation, the algorithm and the computational model is described. In the second part, the resulted computational model is applied to a representative building. The third part includes the discussion of the results and the fourth part conclusions.

\section{METHOD}

This section proposes a method for optimizing evacuation management. The problem to address here is the selection of a set of optimal evacuation routes in real-time. An optimal evacuation route is defined here as the route that produces the minimum evacuation time - "fastest", while keeping occupants away from the hazard -“safest”. 


\section{Formulation}

Given $n_{i}$ potential locations of evacuees (rooms, areas, halls, corridors, etc.) and $n_{j}$ exits, the set of evacuation routes is defined as:

$$
R=\left\{R_{i, j, k} \mid\left(1 \leq i \leq n_{i}\right) \wedge\left(1 \leq j \leq n_{j}\right) \wedge\left(1 \leq k \leq n_{k}(i, j)\right)\right\}
$$

Where:

$R$ - set of evacuation routes available;

$i$ - number of the location of evacuees;

$j$ - number of the exit;

$k$ - number of the evacuation route between $i$-th location and $j$-th exit.

$n_{k}(i, j)$ - total number of available routes between $i$-th location and $j$-th exit.

The first criterion for the method is the evacuation time. In other words, the selected evacuation route for each location is the one that produces the fastest evacuation time, among all alternative routes (evacuation routes available). Therefore, the evacuation route selection, derived from equation (2), is given by:

$$
R_{E R}=\left\{R_{i, j_{1}, k_{1}} \subset R \mid\left(1 \leq j_{1} \leq n_{j}\right) \wedge\left(1 \leq k_{1} \leq n_{k}(i, j)\right) \wedge\left(P_{0.95}\left(T_{\text {evac } i, j_{1}, k_{1}}\right) \leq P_{0.95}\left(T_{\text {evac } i, j_{2}, k_{2}}\right)\left(\forall j_{2} \neq j_{1}\right) \wedge\left(\forall k_{2} \neq k_{1}\right)\right)\right\}
$$

Where:

$R_{E R}$ - set of selected evacuation routes:

$j_{1}, k_{1}$ - selected exit and the evacuation route from each location;

$j_{2}, k_{2}$ - any other exit and evacuation route from each location;

$P_{0.95}(T)$ - 95-th percentile of a given random variable $T$;

$T_{\text {evac } i, j, k}$-evacuation time from $i$-th location to $i$-th exit.

The evacuation time of an occupant can be calculated as follows:

$$
T_{{\text {evac }(i, j, k)_{l}}}=t_{\text {pre }_{(i)_{l}}}+\frac{d_{\text {travel } i, j, k}}{v_{(i, j, k)_{l}}}
$$

Where:

$T_{\text {evac }(i, j, k)_{l}}$ - evacuation time of l-th occupant that uses $R_{i, j, k}$ route;

$T_{\text {pre (i) }}$ - pre-evacuation time of $l$-th occupant from $i$-th location;

$d_{\text {travel } i, j, k}$ - travel distance through $R_{i, j, k}$ route;

$v_{(i, j, k)_{l}}$ - travel speed of $l$-th occupant through $R_{i . j . k}$ route.

Note that this approach focuses on sparsely populated enclosures where evacuation time depends upon the pre-evacuation time of the last few occupants to decide to leave and the time required for them to the exit and walk through it. The travel distance is a deterministic variable whereas the pre-evacuation time and the travel speed are random variables. Therefore, the evacuation time is a random variable too. For simplicity, we suggest paying attention to the evacuation time of the last occupant from each location:

Where:

$$
\left.T_{\text {evac } i, j, k}=\max \left\{T_{\text {evac }(i, j, k)_{l}}\right\}\right\}_{\mid=1}^{m_{w_{i}}}
$$

$\max \left\{x_{l}\right\} \mid \begin{aligned} & m_{w_{i}} \\ & l=1\end{aligned}$ maximum value of $x_{l}$ variable for $1 \leq l<m_{w_{i}} ;$

$m_{w_{i}}-$ number of occupants in $i$-th location.

Up to this point, it is considered that all evacuation routes and exits are available to everyone. However, some routes can become hazardous due to the presence of toxic gases, dangerous materials, risk of explosion, etc., other routes can be lost through deteriorating environmental conditions (smoke, leakages, etc.) and other routes can be blocked. The second criterion for the proposed method is the route availability. Let us divide the floor-map (or maps) of the building into a virtual grid $G$ of cells:

Where:

$$
G=\left\{C_{i x, j y} \mid\left(1 \leq i x \leq n_{i x}\right) \wedge\left(1 \leq j y \leq n_{j y}\right)\right\}
$$

$C_{i x, j y}$ - grid cell; 
$n_{i x}$ - number of columns of the grid;

$n_{j y}-$ number of rows of the grid.

The shape (e.g. square, hexagonal, etc.) and the size of cells may rely on expert-based and/or regulation-based approach. For instance, the European Standard EN 54 part 7 (Smoke detectors) [30] states $6.6 \mathrm{~m}$ as the maximum radio of coverage of detectors for a total surface area greater than $80 \mathrm{~m}^{2}$ and height between 6 and $12 \mathrm{~m}$.

Each cell has two attributes:

Where:

$$
C_{i x, j y}=\left\{A_{v}(i x, j y), R_{i, j, k}(i x, j y)\right\}
$$

$A_{v}(i x, j y)$ - availability to be crossed during evacuation (Boolean variable);

$R_{i, j, k}(i x, j y)$ - evacuation route(s) that cross the cell.

If $A_{v}(i x, j y)=$ false for a given $C_{i x, j y}$ cell, then:

$$
R_{i, j, k}(i x, j y) \rightarrow \hat{R}_{i, j, k}(i x, j y)
$$

Where:

$\hat{R}_{i, j, k}(i x, j y)$ - disabled evacuation route(s) due to $C_{i x, j y}$ cell unavailability.

The set of disabled evacuation routes can be defined as follows:

$$
\hat{R}=U_{i x=1, j y=1}^{n_{i, x} n_{j y}}\left[\hat{R}_{i, j, k}(i x, j y)\right]
$$

The mathematical expression of the method by taking into account the disabled evacuation routes(s) due to the emergency is the following:

$$
R_{E R}=\left\{R_{i, j_{1}, k_{1}} \subset R\left(\begin{array}{l}
\left(1 \leq j_{1} \leq n_{j}\right) \wedge\left(1 \leq k_{1} \leq n_{k}(i, j)\right) \wedge R_{i, j, k} \notin \hat{R} \wedge \\
\left(P_{0.95}\left(T_{\text {evac } i, j_{1}, k_{1}}\right) \leq P_{0.95}\left(T_{\text {evac } i, j_{2}, k_{2}}\right) \mid\left(\forall j_{2} \neq j_{1}\right) \wedge\left(\forall k_{2} \neq k_{1}\right)\right)
\end{array}\right\}\right.
$$

\section{The algorithm}

The described equations imply a numerical solution algorithm and the corresponding computational model. Table 1 displays the set of previous tasks for implementing the method. These tasks define the input variables related to the scenario, the human behavioral data, the statistical processing of these data and the number of runs for the simulation. Figure 1 shows the solution algorithm in pseudocode of C type.

\section{Computational model}

As explained, the solution algorithm should be implemented in a computational model. A specialized model was developed with the purpose to provide the optimal (fastest and safest) evacuation routes from different locations of the evacuees within the building. The model was developed in Visual C\# 2015 following OOP paradigm with different classes devoted to input and output data, evacuation model implementation, Monte Carlo simulations and statistical processing of the samples produced. The model requires as input the variables presented in Table 1 and directly imports this information, in an Excel spreadsheet.

It should be noted that the flexibility of the model allows the user to change input values. Therefore, it is recommended as a good practice to use reliable data from trials and/or evacuation drills in the scenarios where the evacuation models are going to be implemented. Then, the model allows performing hundreds of simulations to generate representative and significant samples of outputs. The Box-Muller transformation [31] is used for sampling from normal and lognormal distributions.

Some routes can become unavailable during an emergency. The floor-map of the building is divided into grid of square cells. In this beta version of the model, the user can select the cells that represent areas directly and/or potentially affected by the emergency by clicking directly on the screen. This information is taken into account for the selection of the optimal evacuation routes. However, it is expected that this information can be automatically implemented as well in the future (e.g. from sensors, a library of fire simulation results, etc.). The outputs include the mean, standard deviation and 95th percentile of evacuation times per route and the selected evacuation route for each location. The method proposed by Hyndman and Fan [32] is used by the model for calculating the percentiles. The model also provides the user the evacuation routes that should not be used by occupants due to the emergency. The results produced displayed at the screen can be saved in txt files as well. 
Table 1. Previous tasks and input variables.

\begin{tabular}{|c|c|c|}
\hline Task & Description & Notation \\
\hline \multirow[t]{3}{*}{$\begin{array}{l}\text { 1 Definition of the } \\
\text { scenario: }\end{array}$} & Number of exits & $n_{j}$ \\
\hline & $\begin{array}{l}\text { Number of potential locations of evacuees } \\
\text { Number of potential evacuation routes }\end{array}$ & $\begin{array}{c}n_{i} \\
n_{k}(i, j)\end{array}$ \\
\hline & Travel distances for each route & $d_{\text {travel } i, j, k}$ \\
\hline \multirow[t]{3}{*}{2 Data collection } & Number of evacuees per location & $m_{w_{i}}$ \\
\hline & $\begin{array}{l}\text { Pre-evacuation time samples per location, where } 1 \leq i \leq n_{i}, 1 \leq l \\
\leq m_{\text {pre }_{i}} \text { and } m_{\text {pre }_{i}} \text { - sample size of pre-evacuation time for } i \text {-th } \\
\text { locations }\end{array}$ & $t_{\text {pre }_{(i)_{l}}}$ \\
\hline & $\begin{array}{l}\text { Walking speed samples per route, where } 1 \leq l \leq m_{v_{i, j, k}} \text { and } \\
m_{v_{i, j, k}} \text { - sample size of walking speed associated to the } R_{i, j, k} \text {, } \\
\text { route }\end{array}$ & $V_{(i, j, k)_{l}}$ \\
\hline \multirow[t]{4}{*}{3 Statistical processing } & Means of pre-evacuation times and walking speeds & $m\left(t_{\text {pre }_{i}}\right), m\left(v_{i, j, k}\right)$ \\
\hline & Standard deviations of pre-evacuation times and walking speeds & $s\left(t_{\text {pre }_{i}}\right), s\left(v_{i, j, k}\right)$ \\
\hline & $\begin{array}{l}\text { Distribution fitting, where } x-\text { random variable and } D_{f i t}(x)=0,1 \text {, } \\
\text { 2: }\end{array}$ & \\
\hline & $\begin{array}{l}\text { - } \quad 0 \text { - normal distribution } \\
\text { - } 1 \text { - lognormal distribution } \\
\text { - } 2 \text { - uniform distribution }\end{array}$ & $D_{f i t}(x)$ \\
\hline 4 Number of runs & Definition of the number of iterations for the simulation & $m_{\text {run }}$ \\
\hline
\end{tabular}

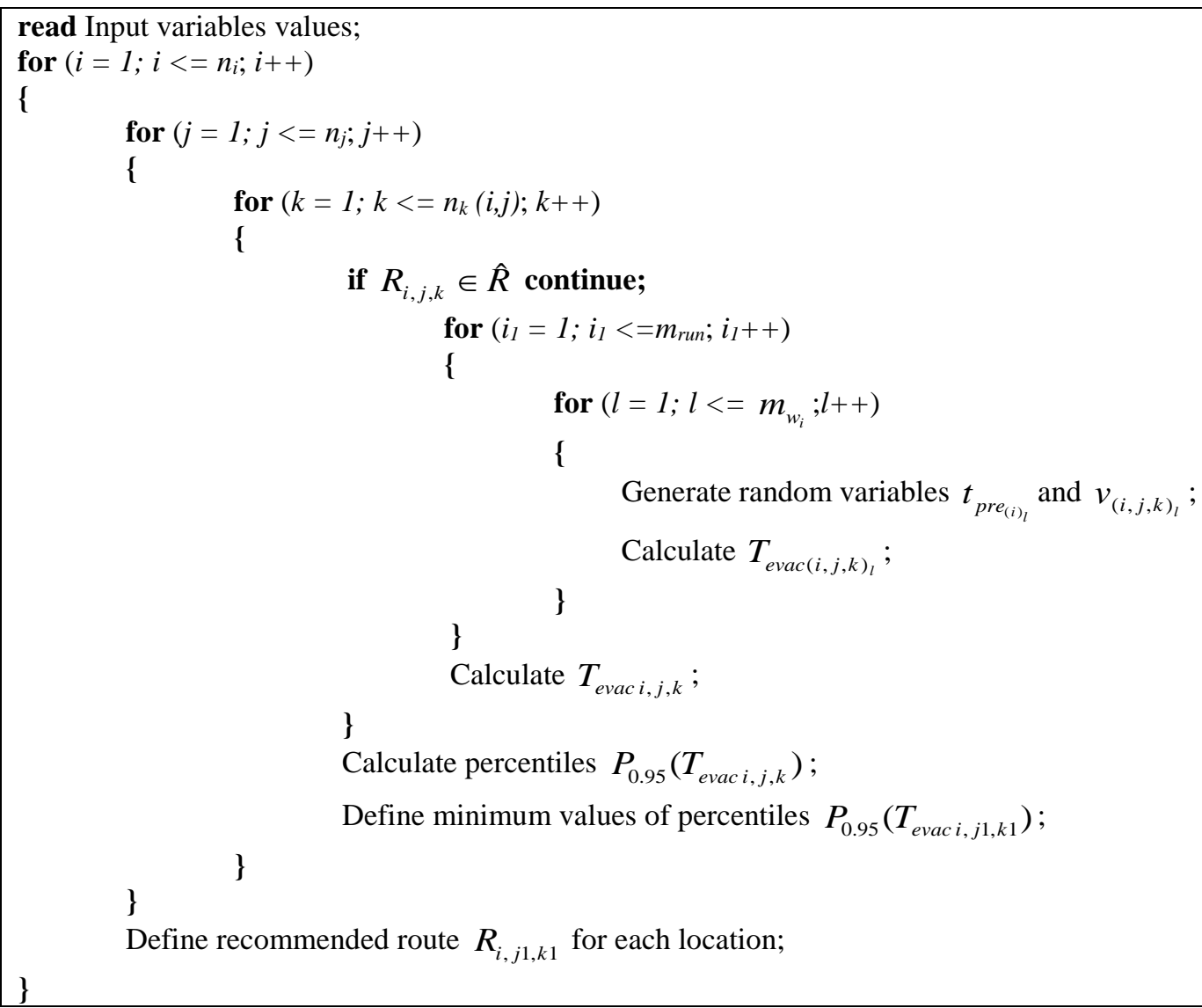

Fig. 1. The solution algorithm in pseudocode of C. 


\section{APPLICATION}

In the following, the computational model is applied to a representative sample. First, the selected building is described. Second, the proposed evacuation model is compared with the commercial evacuation model STEPS [33]. Third, the validity of the model is illustrated by two tests. In Test 1 no emergency is considered in order to check that the software provides the fastest evacuation routes for workers of the factory. In Test 2 several emergencies are considered in different locations in order to check that the model is flexible enough and provides strategies based on fastest and safest evacuation routes.

\section{The building}

The selected building is a single story factory for the production of starter motors and generators. Figure 2 shows the layout of the factory, the starting locations of evacuees (working areas), the number of evacuees per location and the exits available. The adjacent two-story office building of the factory is not considered in this analysis. In total 34 potential evacuation routes are identified. Figures 3-8 show the paths of the potential evacuation routes and the travel distances from each working area. The travel distances were measured from the central point of each working area to each exit, having regard to the layout of the factory (see Figure 2).

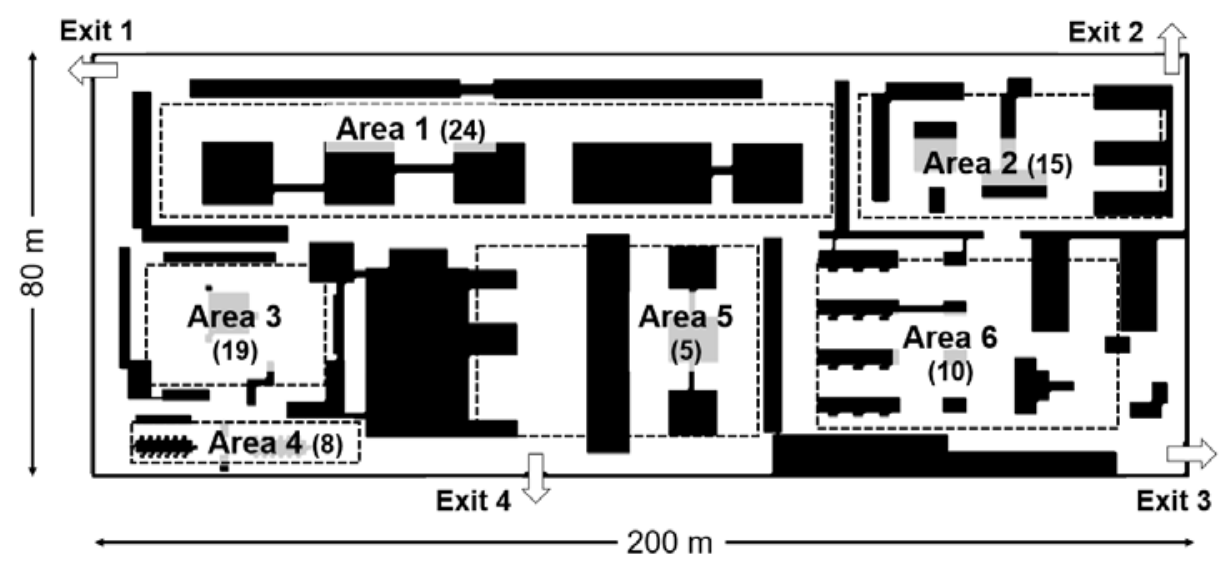

Fig. 2. Layout of the factory, working areas, number of workers per area and exits.

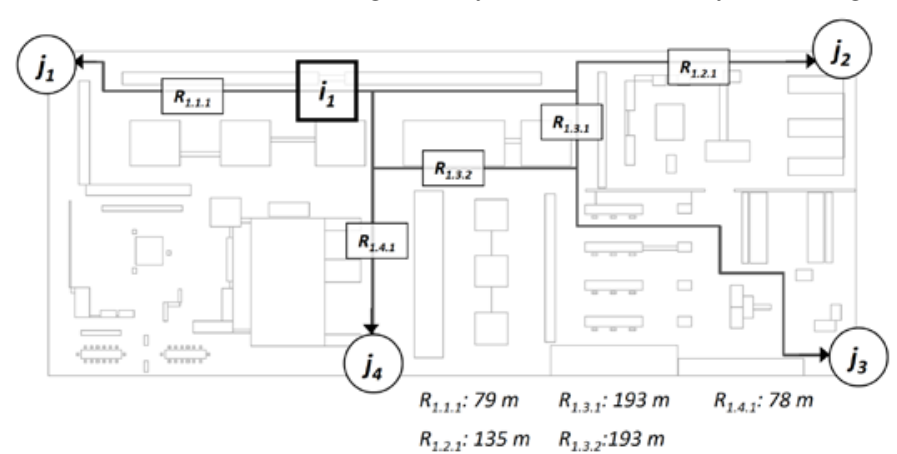

Fig. 3. Potential evacuation routes from Area 1.

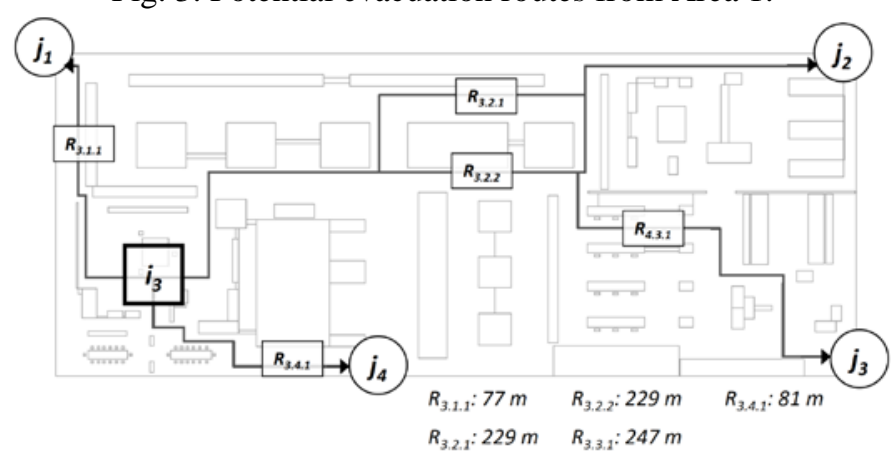

Fig. 5. Potential evacuation routes from Area 3.

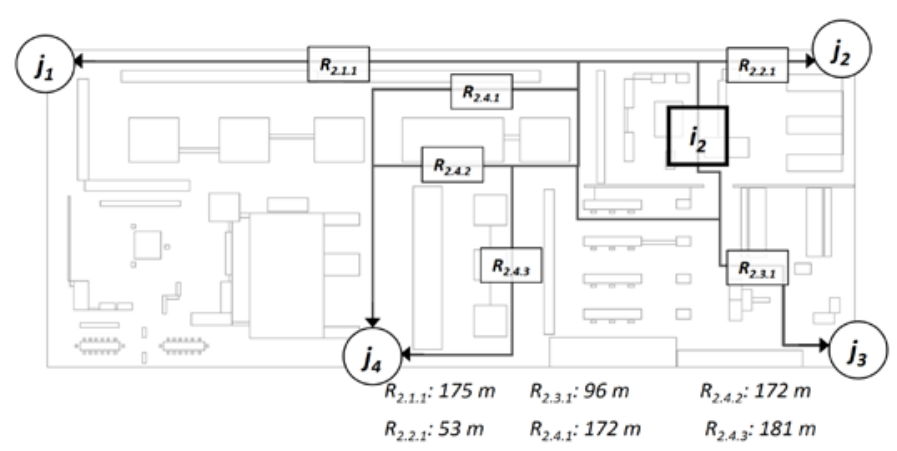

Fig. 4. Potential evacuation routes from Area 2.

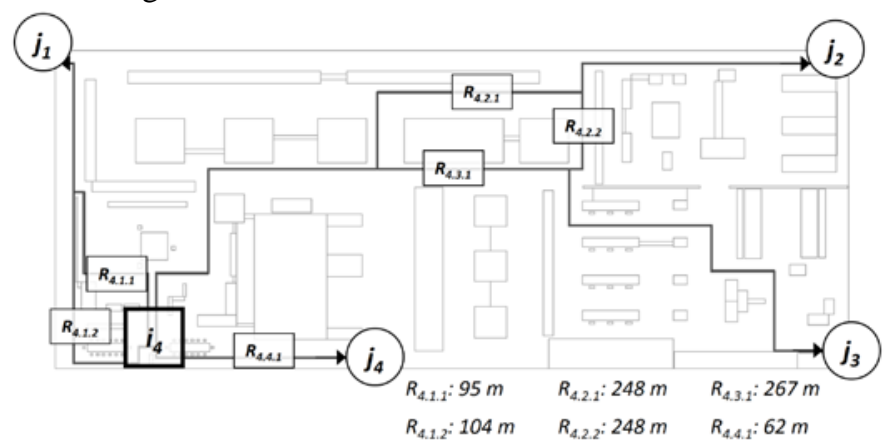

Fig. 6. Potential evacuation routes from Area 4. 


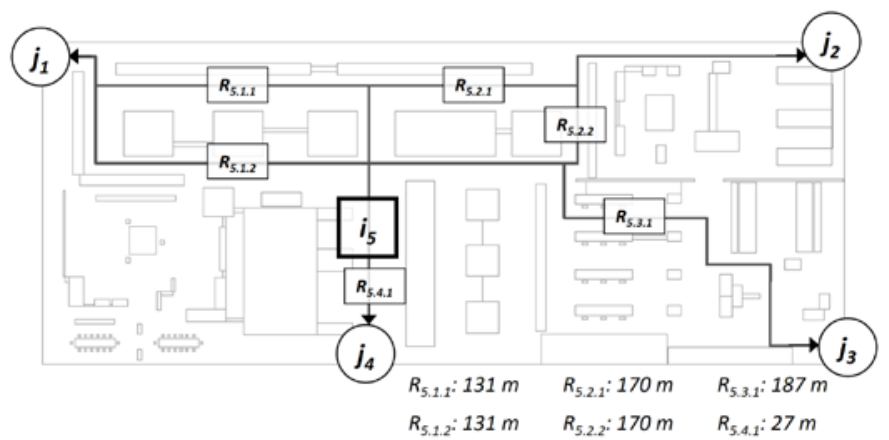

Fig. 7. Potential evacuation routes from Area 5.

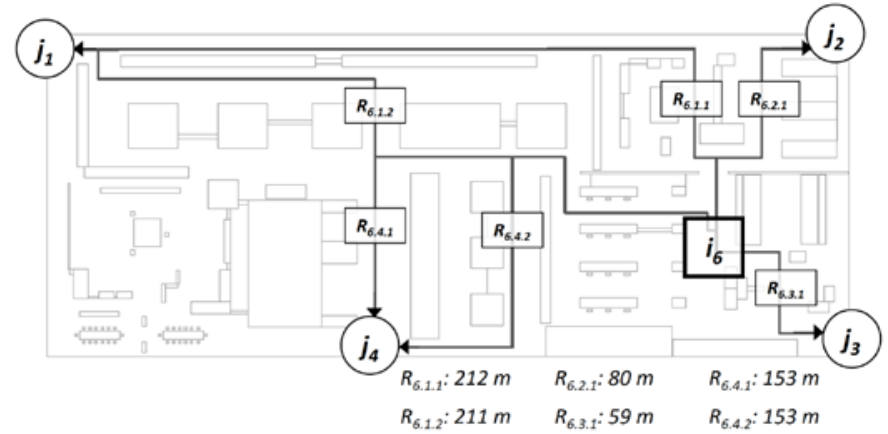

Fig. 8. Potential evacuation routes from Area 6.

\section{Comparison of the proposed evacuation model with STEPS}

The proposed evacuation model was compared with the commercial evacuation model STEPS. The comparative analysis involved 14 potential evacuation routes: $R_{1.1 .1}, R_{1.4 .1}, R_{2.1 .1}, R_{2.3 .1}, R_{3.1 .1}, R_{4.1}, R_{4.1 .1}, R_{4.2 .1}, R_{4.4 .1}, R_{5.3 .1} R_{.4 .1}, R_{6.1 .1}$ and $R_{6.3 .1}$ (see Figures 3-8). In industrial and manufacturing properties, the pre-evacuation time is highly dependent on the working area. For instance, some workers may remain to shut down critical operations before evacuating. They can be required to shut down gas and electrical systems and other special equipment that could be damaged if left operating or create additional hazards. In addition, equipment such as ear protectors may contribute to delays in starting evacuation. In this analysis, pre-evacuation times were introduced in the models assuming different hypothetical normal distributions for each working area. The travel speeds also vary between evacuation routes due to the presence of stairs, narrow corridors, etc. Also, different normal distributions were assumed as input for each working area. The input values are displayed in Table 2. Each model was run using the known occupant loads (see Figure 2). The evacuation was simulated 100 times to capture potential outcomes.

Table 2. Inputs for the comparative analysis of evacuation models.

\begin{tabular}{ccccc} 
& \multicolumn{2}{c}{ Pre-evacuation (s) } & \multicolumn{2}{c}{ Walking Speed (m/s) } \\
\hline Area & Mean & $\begin{array}{c}\text { Standard } \\
\text { Deviation }\end{array}$ & Mean & Standard Deviation \\
\hline 1 & 87.3 & 21.2 & 1.34 & 0.24 \\
2 & 92.5 & 23.6 & 1.25 & 0.24 \\
3 & 58.6 & 10.2 & 1.36 & 0.23 \\
4 & 89.4 & 24.8 & 1.65 & 0.17 \\
5 & 122.3 & 18.7 & 1.53 & 0.21 \\
6 & 148.2 & 22.8 & 1.40 & 0.23 \\
\hline
\end{tabular}

The comparison results indicate small differences produced by the proposed model and STEPS. As Figure 9 shows, the relative errors (for the means and the $95^{\text {th }}$ percentiles) of evacuation times produced are lower than 0.15 while taking into account the random starting location of the agents in STEPS and the random inputs. Therefore, it is possible to say that the proposed model is able to provide as reliable predictions as the model of the comparison.
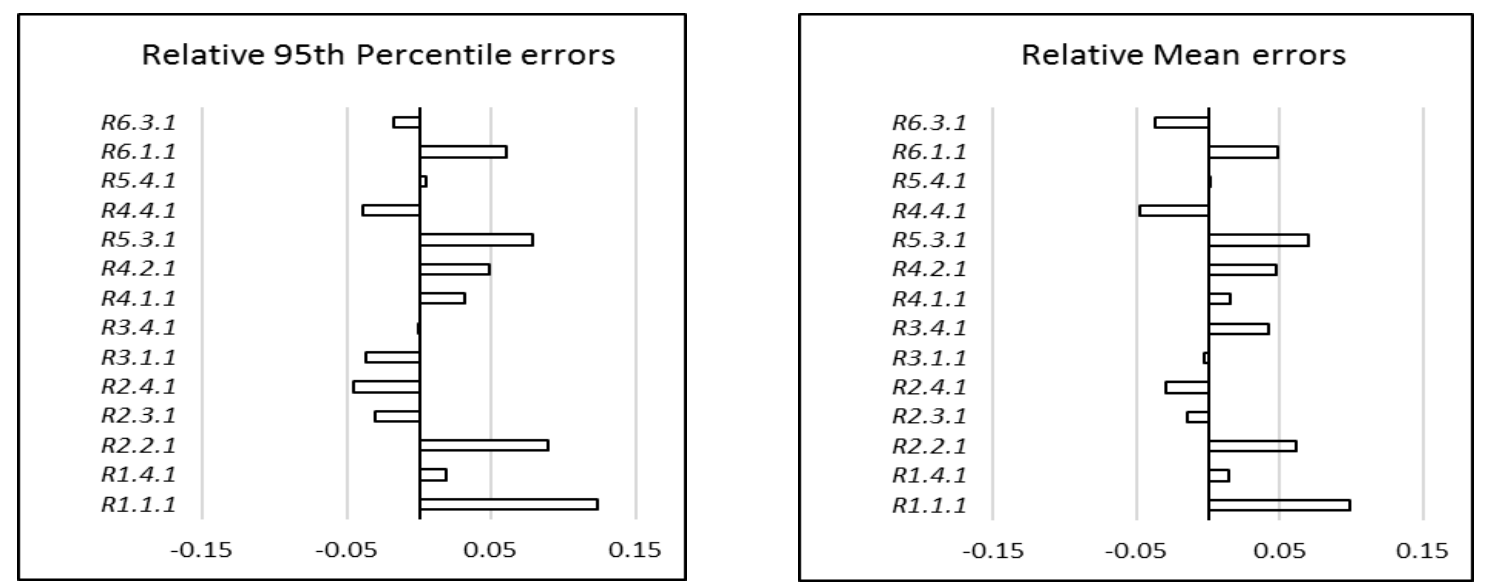

Fig. 9. Relative errors for means and 95the percentiles of evacuation times produced by STEPS and the proposed evacuation model. 


\section{Test 1}

This test represents a full evacuation with all evacuation routes available. The inputs were the same used for the evacuation model comparison (see Table 2). The scenario was run 1.000 times and the results were displayed at the screen in a few seconds. Table 3 shows the 1, 3 and 4 while workers in Area 2 are recommended to use Exit 2 and workers in Area 5 Exit 3.

Table 3. Results of Test 1.

\begin{tabular}{|c|c|c|c|c|c|}
\hline \multirow{2}{*}{ Area } & \multirow{2}{*}{ Route } & \multicolumn{3}{|c|}{ Evacuation time (s) } & \multirow{2}{*}{$\begin{array}{c}\text { Route } \\
\text { selected }\end{array}$} \\
\hline & & Mean & S.D.* & 95th Perc. & \\
\hline \multirow[t]{5}{*}{1} & $R_{1.1 .1}$ & 207 & 22 & 260 & \\
\hline & $R_{1.2 .1}$ & 262 & 22 & 313 & \\
\hline & $R_{1.3 .1}$ & 328 & 39 & 399 & \\
\hline & $R_{1.3 .2}$ & 312 & 36 & 397 & \\
\hline & $R_{1.4 .1}$ & 199 & 15 & 228 & $\mathrm{OK}$ \\
\hline \multirow[t]{6}{*}{2} & $R_{2.1 .1}$ & 334 & 69 & 440 & \\
\hline & $R_{2.2 .1}$ & 184 & 15 & 209 & OK \\
\hline & $R_{2.3 .1}$ & 227 & 21 & 269 & \\
\hline & $R_{2.4 .1}$ & 327 & 51 & 443 & \\
\hline & $R_{2.4 .2}$ & 303 & 32 & 385 & \\
\hline & $R_{2.4 .3}$ & 331 & 55 & 436 & \\
\hline \multirow[t]{5}{*}{3} & $R_{3.1 .1}$ & 154 & 17 & 197 & \\
\hline & $R_{3.2 .1}$ & 331 & 49 & 416 & \\
\hline & $R_{3.2 .2}$ & 291 & 21 & 334 & \\
\hline & $R_{3.3 .1}$ & 339 & 39 & 410 & \\
\hline & $R_{3.4 .1}$ & 159 & 16 & 197 & OK \\
\hline \multirow[t]{6}{*}{4} & $R_{4.1 .1}$ & 186 & 18 & 225 & \\
\hline & $R_{4.1 .2}$ & 192 & 16 & 228 & \\
\hline & $R_{4.2 .1}$ & 286 & 21 & 329 & \\
\hline & $R_{4.2 .2}$ & 280 & 18 & 318 & \\
\hline & $R_{4.3 .1}$ & 298 & 22 & 340 & \\
\hline & $R_{4.4 .1}$ & 163 & 16 & 192 & OK \\
\hline \multirow[t]{6}{*}{5} & $R_{5.1 .1}$ & 238 & 16 & 269 & \\
\hline & $R_{5.1 .2}$ & 233 & 16 & 262 & \\
\hline & $R_{5.2 .1}$ & 265 & 19 & 295 & \\
\hline & $R_{5.2 .2}$ & 263 & 21 & 305 & \\
\hline & $R_{5.3 .1}$ & 281 & 23 & 352 & \\
\hline & $R_{5.4 .1}$ & 161 & 12 & 183 & OK \\
\hline \multirow[t]{6}{*}{6} & $R_{6.1 .1}$ & 371 & 38 & 457 & \\
\hline & $R_{6.1 .2}$ & 368 & 38 & 438 & \\
\hline & $R_{6.2 .1}$ & 244 & 16 & 273 & \\
\hline & $R_{6.3 .1}$ & 230 & 16 & 259 & OK \\
\hline & $R_{6.4 .1}$ & 311 & 24 & 353 & \\
\hline & $R_{6.4 .2}$ & 312 & 23 & 352 & \\
\hline
\end{tabular}

* Standard Deviation

\section{Test 2}

Test 2 provides the opportunity to assess the results of the computational model in different emergency scenarios. As explained, the model divides the floor-map of the building into a grid of square cells. We assumed a grid size of $10 \mathrm{x} 10 \mathrm{~m}$. Hence, the factory ( 200 x $80 \mathrm{~m}$ ) was divided into a grid of 160 numbered cells. The grid is used to represent areas directly and/or potentially affected by the emergency (i.e. a safety perimeter). Some cells have no impact on the evacuation system and other cells can make evacuation routes unavailable and/or undesirable. This feature allows the model to consider this when simulating the potential evacuation strategies. In total 10 emergency scenarios were tested. Figure 10 shows the scenarios with the floor-map of the factory and the disabled cells for evacuation. 
Scenarios 1-4 represent affected areas that block one exit and scenarios 5-6 represent separated areas that block two exits. This can be unrealistic but useful, however, for model assessment. The inputs in relation to the number and location of the workers (see Figure 2), the pre-evacuation time and the walking speed distributions (see Table 2) are the same used in previous analyses. Each scenario was run 1.000 times and results were processed and displayed within a few seconds (from 5 to $10 \mathrm{~s}$ ).

Scenario 1

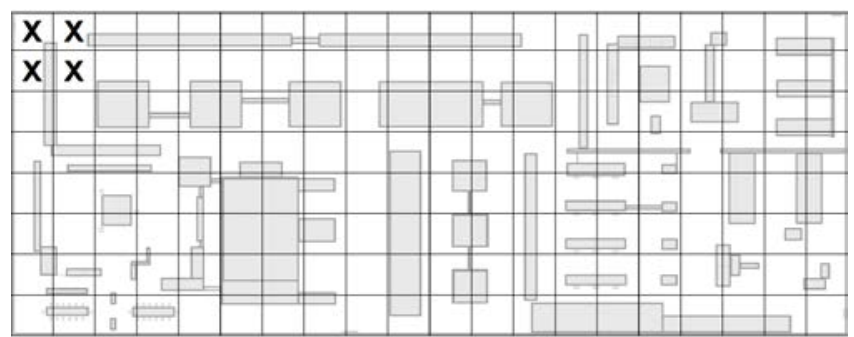

Scenario 3

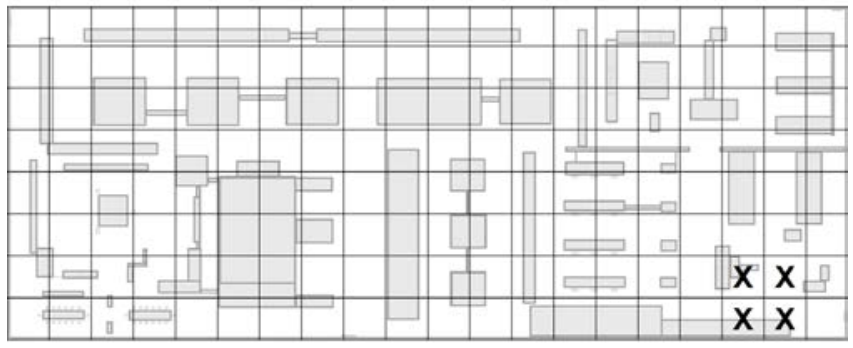

Scenario 5

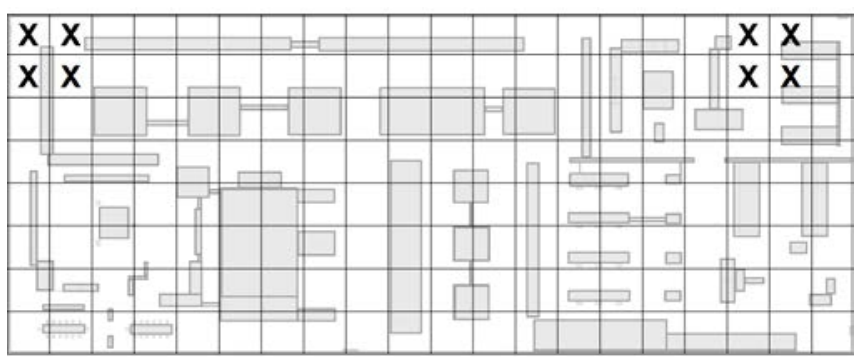

Scenario 7

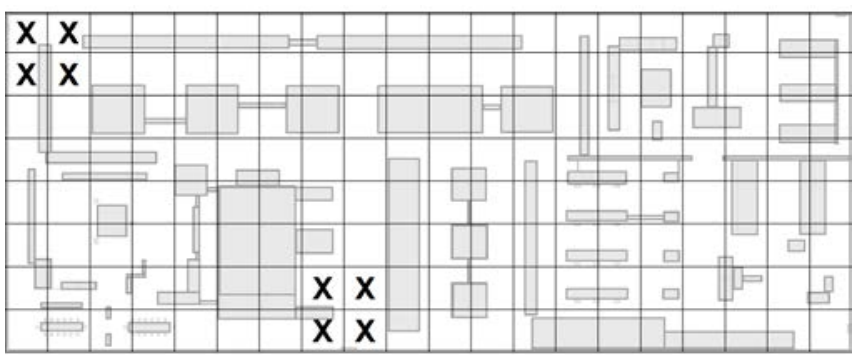

Scenario 9

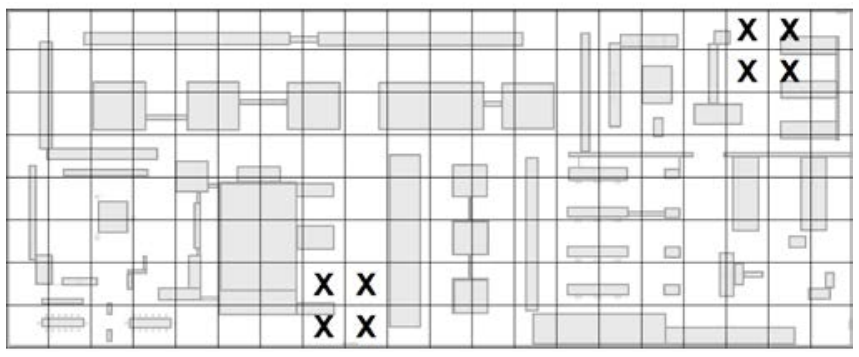

Scenario 2

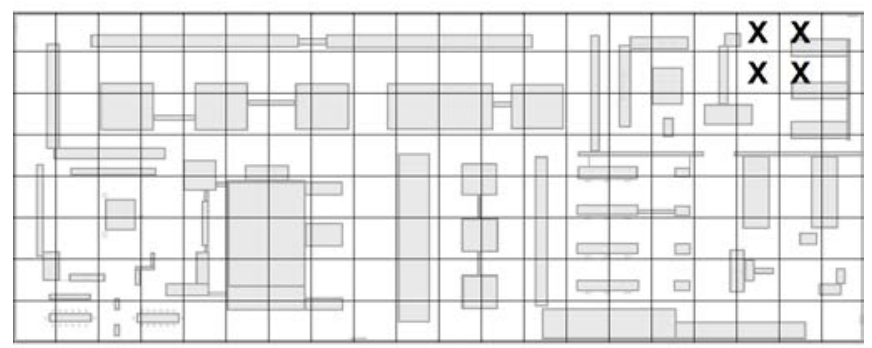

Scenario 4

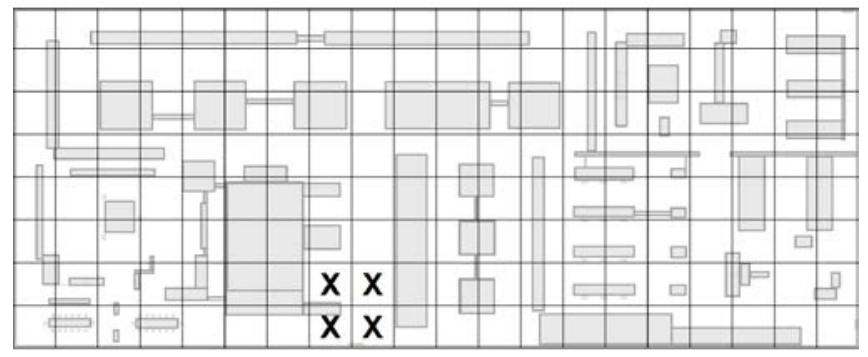

Scenario 6

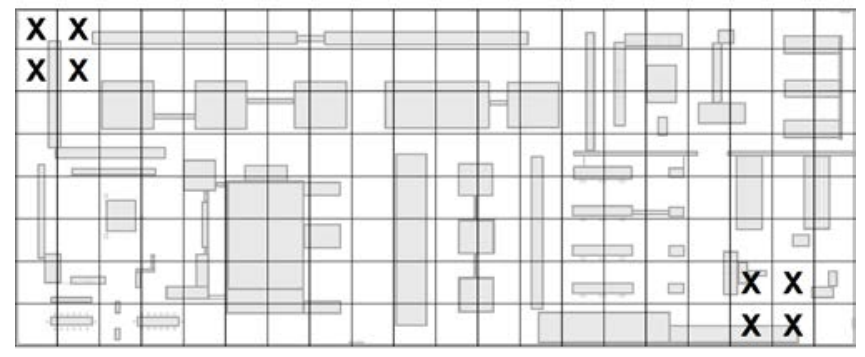

Scenario 8

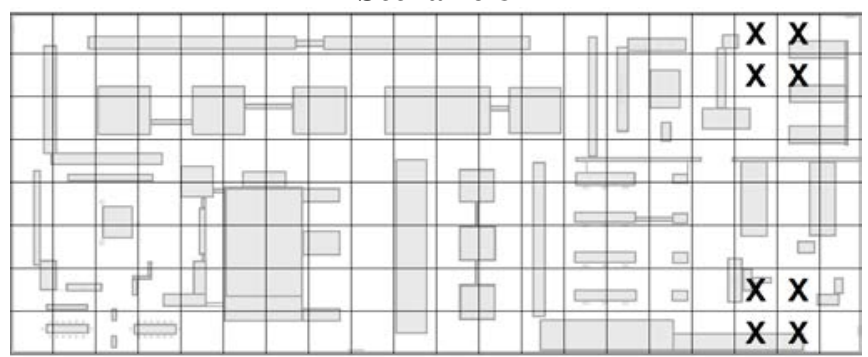

Scenario 10

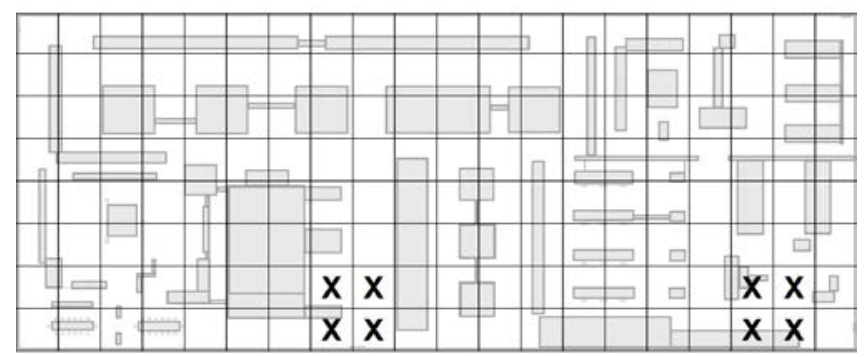

Fig. 10. Emergency scenarios for Test 2.

Table 4 shows the optimal evacuation strategies for simultaneous full evacuation of the factory under different hypothetical emergencies. The information in Table 4 can be contrasted with the path description from Figures 3-8 and the locations of the emergency from Figure 10. The generated results provide the optimal evacuation routes for each area (location) within the building. The model also provides information of the evacuation routes availability and evacuation time predictions for each route according 
to different emergency conditions. The model recommends fastest evacuation far from the affected areas. Therefore, it is possible to say that the model performs its required functions under stated conditions. Again, it is important to mention that these computerbased analyses of each emergency scenario took a few seconds. Therefore, it is argued here that the proposed model can be used to make critical decisions during the first stages of the emergency. Furthermore, the user can explore different evacuation processes and represent the new scenarios dynamically.

Table 4. Results of scenarios analyzed in Test 2.

\begin{tabular}{|c|c|c|c|c|c|c|c|c|c|c|c|}
\hline \multirow{2}{*}{ Area } & \multirow{2}{*}{ Route } & \multicolumn{9}{|c|}{ Scenarios } & \multirow[b]{2}{*}{10} \\
\hline & & 1 & 2 & 3 & 4 & 5 & 6 & 7 & 8 & 9 & \\
\hline \multirow[t]{5}{*}{1} & $R_{1.1 .1}$ & $\mathrm{X}$ & - & OK & OK & $\mathrm{X}$ & $\mathrm{X}$ & $\mathrm{X}$ & OK & OK & OK \\
\hline & $R_{1.2 .1}$ & - & $\mathrm{X}$ & - & - & $\mathrm{X}$ & - & OK & $X$ & $\mathrm{X}$ & - \\
\hline & $R_{1.3 .1}$ & - & - & $X$ & - & - & $X$ & - & $X$ & - & $\mathrm{X}$ \\
\hline & $R_{1.3 .2}$ & - & - & $\mathrm{X}$ & - & - & $X$ & - & $\mathrm{X}$ & - & $\mathrm{X}$ \\
\hline & $R_{1.4 .1}$ & $\mathrm{OK}$ & $\mathrm{OK}$ & - & $X$ & $\mathrm{OK}$ & $\mathrm{OK}$ & $\mathrm{X}$ & - & $X$ & $X$ \\
\hline \multirow[t]{6}{*}{2} & $R_{2.1 .1}$ & $X$ & - & - & - & $\mathrm{X}$ & $X$ & $X$ & - & - & - \\
\hline & $R_{2.2 .1}$ & $\mathrm{OK}$ & $\mathrm{X}$ & $\mathrm{OK}$ & $\mathrm{OK}$ & $\mathrm{X}$ & $\mathrm{OK}$ & OK & $X$ & $X$ & $\mathrm{OK}$ \\
\hline & $R_{2.3 .1}$ & - & OK & $\mathrm{X}$ & - & OK & $\mathrm{X}$ & - & $X$ & OK & $\mathrm{X}$ \\
\hline & $R_{2.4 .1}$ & - & - & - & $\mathrm{X}$ & - & - & $X$ & - & $\mathrm{X}$ & $X$ \\
\hline & $R_{2.4 .2}$ & - & - & - & $\mathrm{X}$ & - & - & $X$ & OK & $\mathrm{X}$ & $\mathrm{X}$ \\
\hline & $R_{2.4 .3}$ & - & - & - & $X$ & - & - & $X$ & - & $X$ & $\mathrm{X}$ \\
\hline \multirow[t]{5}{*}{3} & $R_{3.1 .1}$ & $X$ & $\mathrm{OK}$ & $\mathrm{OK}$ & $\mathrm{OK}$ & $X$ & $X$ & $X$ & OK & OK & OK \\
\hline & $R_{3.2 .1}$ & - & $X$ & - & - & $X$ & - & - & $X$ & $X$ & - \\
\hline & $R_{3.2 .2}$ & - & $\mathrm{X}$ & - & - & $X$ & - & OK & $X$ & $X$ & - \\
\hline & $R_{3.3 .1}$ & - & - & $X$ & - & - & $X$ & - & $X$ & - & $X$ \\
\hline & $R_{3.4 .1}$ & $\mathrm{OK}$ & - & - & $X$ & $\mathrm{OK}$ & $\mathrm{OK}$ & $X$ & - & $X$ & $\mathrm{X}$ \\
\hline \multirow[t]{6}{*}{4} & $R_{4.1 .1}$ & $X$ & - & - & $\mathrm{OK}$ & $X$ & $X$ & $X$ & - & $\mathrm{OK}$ & $\mathrm{OK}$ \\
\hline & $R_{4.1 .2}$ & $X$ & - & - & - & $X$ & $X$ & $X$ & - & - & - \\
\hline & $R_{4.2 .1}$ & - & $\mathrm{X}$ & - & - & $X$ & - & - & $X$ & $X$ & - \\
\hline & $R_{4.2 .2}$ & - & $\mathrm{X}$ & - & - & $X$ & - & OK & $X$ & $X$ & - \\
\hline & $R_{4.3 .1}$ & - & - & $X$ & - & - & $X$ & $X$ & $X$ & - & $X$ \\
\hline & $R_{4.4 .1}$ & $\mathrm{OK}$ & OK & $\mathrm{OK}$ & $X$ & $\mathrm{OK}$ & OK & $X$ & OK & $X$ & $X$ \\
\hline \multirow[t]{6}{*}{5} & $R_{5.1 .1}$ & $X$ & - & - & - & $X$ & $X$ & $X$ & - & - & OK \\
\hline & $R_{5.1 .2}$ & - & - & - & $\mathrm{OK}$ & $X$ & $X$ & $X$ & - & OK & - \\
\hline & $R_{5.2 .1}$ & - & $\mathrm{X}$ & - & - & $X$ & - & OK & $X$ & $X$ & - \\
\hline & $R_{5.2 .2}$ & - & $X$ & - & - & $X$ & - & - & $X$ & $X$ & - \\
\hline & $R_{5.3 .1}$ & - & - & $X$ & - & -- & $X$ & - & $X$ & - & $X$ \\
\hline & $R_{5.4 .1}$ & OK & OK & OK & $X$ & $\mathrm{OK}$ & $\mathrm{OK}$ & $X$ & OK & $X$ & $X$ \\
\hline \multirow[t]{6}{*}{6} & $R_{6.1 .1}$ & $X$ & - & - & - & $X$ & $X$ & $X$ & - & - & - \\
\hline & $R_{6.1 .2}$ & - & - & - & - & $X$ & $X$ & $X$ & - & - & - \\
\hline & $R_{6.2 .1}$ & - & $X$ & - & - & $X$ & $\mathrm{OK}$ & - & $X$ & $X$ & $\mathrm{OK}$ \\
\hline & $R_{6.3 .1}$ & $\mathrm{OK}$ & OK & $X$ & OK & $\mathrm{OK}$ & $X$ & OK & $X$ & OK & $X$ \\
\hline & $R_{6.4 .1}$ & - & - & - & $X$ & - & - & $X$ & - & $X$ & $X$ \\
\hline & $R_{6.4 .2}$ & - & - & - & $\mathrm{X}$ & - & - & & OK & - & - \\
\hline $\mathrm{OK}$ & Selectec & aste & ind s & est) & & & & & & & \\
\hline - & Availab & & & & & & & & & & \\
\hline
\end{tabular}

\section{CONCLUSION}

A new decision method has been proposed for generating optimal evacuation routes in real-time. The method involves the mathematical formulation, the optimization algorithm and the computational model, which operates taking into account the location of the hazard. 
The optimization algorithm is based on stochastic evacuation model predictions. The evacuation model simulates the potential evacuation scenarios in which occupants are directed toward a variety of exits. The optimization algorithm is able to determine, based on the evacuation results, the evacuation route that will minimize the time required to evacuate all occupants from each location within the building. This evacuation model has been compared to another validated evacuation model. Clearly, the results of the comparison suggest that the stochastic model can provide consistent and reliable results.

The computational model has been tested in representative building: a factory with multiple evacuation route choices for workers. Two tests have been performed in order to check that the computational model is working satisfactory. In Test 1 no emergency was considered. In Test 2 several emergency scenarios were tested.

From this work, it is concluded that proposed method can be used for supporting timely decisions during actual emergencies. It should be note that, while this paper concentrates on fire incidents, the proposed method is applicable also to other emergencies such as terrorist attacks, spillages, explosions, etc.

The current version of the proposed model has limitations. For instance, the evacuation model focuses on sparsely occupied enclosures. In addition, no automatic detection and threat propagation model is incorporated so the user must select manually the location of the hazard within the floor-map of the building. It should be noted that, the computational model has been integrated into an evacuation support system prototype and tested in a relevant environment. Nevertheless, the results of this proof of concept go beyond the scope this paper.

\section{ACKNOWLEDMENTS}

The authors would like to acknowledge the Spanish Ministry of Economy and Competitiveness for the DEFENDER Project grant, Ref: BIA2016-64866-R, co-financed by ERDS funds.

\section{REFERENCES}

[1] Kimura, M. and Sime, J.D. "Exit Choice Behavior During The Evacuation of Two Lecture Theatres”, Proceedings of the second International Symposium, International Association for Fire Safety Science, 1989, pp. 541-550.

[2] Jin, T., Yamada, T., Kawai, S. and Takahashi, S., "Evaluation of the Conspicuousness of Emergency Exit Signs". Proceedings of the third International Symposium, International Association for Fire Safety Science, 1991, pp. 835-841.

[3] Paulsen, T., “The Effect of Escape Route Information on Mobility And Way Finding Under Smoke Logged Conditions”, Proceedings of the fourth International Symposium, International Association for Fire Safety Science, 1994, pp. 693-704.

[4] Gwynne, S., Galea, E.R., Lawrence, P.J., Owen, M. and Filippidis, L., “Adaptive Decision-making in Building Exodus in Response To Exit Congestion”, Proceedings of the sixth International Symposium, International Association for Fire Safety Science, 2000, pp. 1041-1052.

[5] Nilsson, D., Frantzich, H. and Saunders, W.L., “Influencing Exit Choice in the Event of a Fire Evacuation”. Proceedings of the ninth International Symposium, International Association for Fire Safety Science, 2008, pp. 341-352.

[6] Filippidis, L., Lawrence, P.J., Galea, E.R. and Blackshields, D., "Simulating the Interaction of Occupants with Signage Systems”. Proceedings of the ninth International Symposium, International Association for Fire Safety Science, 2008, pp. 389-400.

[7] Veeraswamy, A., Galea, E.R. and Lawrence, P.J., "Wayfinding Behavior within Buildings - An International Survey”. Proceedings of the tenth International Symposium, International Association for Fire Safety Science, 2011, pp. 735-748.

[8] Korhonen, T. and Heliövaara, S., “FDS+Evac: Herding Behavior and Exit Selection”, Proceedings of the tenth International Symposium, International Association for Fire Safety Science, 2011, pp. 723-734.

[9] Galea, E.R., Xie H. and Lawrence, P.J., "Experimental and Survey Studies on the Effectiveness of Dynamic Signage Systems”, Proceedings of the eleventh International Symposium, International Association for Fire Safety Science, 2014, pp. 1129-1143.

[10] Haghani, M. and Sarvi, M., (2016), Human exit choice in crowded built environments: Investigating underlying behavioural differences between normal egress and emergency evacuations, Fire Safety Journal 85, 1-9.

[11] Mesmer, B.L., and Bloebaum, C. L, (2014), Incorporation of decision, game Bayesian game theory in an emergency evacuation exit decision model, Fire Safety Journal 67, 121-134.

[12] D’Órazio, M. and Longhi, S., (2016), Fire exit signs: the use of neurological activity analysis for quantitative evaluations on their perceptiveness in a virtual environment, Fire Safety Journal 82, 63-75.

[13] Hamacher, Horst W., and Stevanus A. Tjandra. Mathematical modelling of evacuation problems: A state of art. Fraunhofer-Institut für Techno-und Wirtschaftsmathematik, Fraunhofer (ITWM), 2001 
[14] Kisko, T.M, and Francis, R.L., (1985) Evacnet+: a computer program to determine optimal evacuation plans, Fire Safety Journal 9, 211-220.

[15] Kostrva, M.M., Wiecek, M.M. and Gatachew, T. “Optimization Models In Fire Egress Analysis For Residential Buildings”. Proceedings of the third International Symposium, 1991, pp. 805-814.

[16] García-Ojeda, J.C., et al., (2013) Building-evacuation-route planning via time-expanded process-network synthesis, Fire Safety Journal 61, 338-347.

[17] Takahasi, K., Tanaka, T. and Kose, SD. “An Evacuation Model for Use in Fire Safety Design of Buildings”, Fire Safety Science -- Proceedings of the second International Symposium, International Association for Fire Safety Science, 1989, pp. 511-560.

[18] Gwynne, S., et al., (1999) A Review of the Methodologies Used in the Computer Simulation of Evacuation from Building Environment, Building and Environment 34, 741-749.

[19] Tabares, R. M., (2009) Evacuation Process Versus Evacuation Models: “Quo Vadimus?”, Fire Technology 45, 419-430.

[20] Gwynne, S., and Kuligowski, E., “Application Modes of Egress Simulations”, Proceedings of the ${ }^{\text {th }}$ International Conference Pedestrian and Evacuation Dynamics, Springer, 2008, pp.397-409.

[21] Lin, Y., et al., “Agent-Based Simulation of Evacuation: An Office Building Case Study”, Proceedings of the $4^{\text {th }}$ International Conference Pedestrian and Evacuation Dynamics, Springer, 2008, pp.345-357.

[22] Capote, J. A., Alvear, D. M., Abreu, O. V., Cuesta, A. and Alonso, V., (2012) A Stochastic Approach for Simulation Human Behavior during Evacuation Process in Passenger Trains, Fire Technology 48: 911-925.

[23] Capote, J. A., Alvear, D. M., Abreu, O. V. and Cuesta, A., (2012) Analysis of evacuation procedures in high-speed trains fires, Fire Safety Journal 49, 35-46.

[24] Cuesta, A., Abreu, O. and Alvear, D. "Future challenges in evacuation modelling”, Evacuation modelling trends, Arturo Cuesta, Orlando Abreu and Daniel Alvear, Springer, UK, 2016, p. 103-131.

[25] Cuesta A., Alvear, D., Abreu O. and Silió D., "Real-time Stochastic Evacuation Models for Decision Support in Actual Emergencies. Proceedings of the eleventh International Symposium, International Association for Fire Safety Science, 2014, 1063-1076.

[26] Capote, J. et al. (2013), A real-time evacuation model for road tunnels, Safety Science 52, 73-80.

[27] Alvear, D. et al. (2013), Decision support system for emergency management: Road tunnels, Tunneling and Underground Space Technology 34, 13-21.

[28] Capote, A., Alvear, D., Abreu, O., Cuesta, A., and Alonso, V., (2013) A real-time stochastic evacuation model for Road tunnels, Safety Science 52, 73-80.

[29] Yamashita, T., et al. “Exhaustive testing plan with high speed evacuation simulator”, Proceedings of the International Scientific Conference Emergency Evacuation of People from Buildings, 2011, pp.357-363.

[30] BS EN 54-7:2001, Fire detection and Fire alarm system, Part 7: Smoke detectors - point detectors using scattered light, transmitted light or ionization, The European Standard, 2001.

[31] Box, G.E.P. Box, and Muller, M.E. Muller (1958) A Note on the Generation of Random Normal Deviates, The Annals of Mathematical Statistics 29, 610-611.

[32] Hyndman, J., and Fan, Y. (1996), Sample quantiles in statistical packages, The American Statistician, 50, $361-365$.

[33] STEPS Simulation of Transient and Pedestrian movementS: User Manual, unpublished, available with egress model from Mott MacDonald. http://www.mottmac.com. 